Article

\title{
Experimental Study on Dynamic and Thermal Behaviour of Chopped Glass, Sisal, and Flax Fiber-Reinforced Gears
}

\author{
C. M. Meenakshi Dhanushkodi ${ }^{(D)}$ and Krishnamoorthy Arunagri * (D) \\ Department of Mechanical Engineering, Sathyabama Institute of Science and Technology, Chennai 600119, \\ Tamil Nadu, India; cmmeenakshi84@gmail.com \\ * Correspondence: akrishnamoorthy.mech@sathyabama.ac.in; Tel.: +91-944-428-4037
}

Received: 9 July 2018; Accepted: 14 August 2018; Published: 20 August 2018

\begin{abstract}
Recently, there has been rapid growth in research and innovation in natural fiber composites. The main reasons for the interest on these reinforcements over synthetic fiber reinforcements are their low environmental impact, low cost, and high flexural strength, which supports their potential across a wide range of applications. One of the promising applications of polymeric composite is polymeric gears, used in power and motion transmission work under different loads and speeds. In this work, polymeric spur gears are manufactured with various reinforcements like glass, sisal, and flax fiber in $15 \%$ and $20 \%$ weight percentage, and the gears are produced by molding process. The performance and wear of the gears are tested using a dynamic testing procedure. The tested gears are analyzed for modifications in tooth profile using scanning electron microscope. The weight loss as well as the thermal capability is studied using a contactless infra-red temperature (FLIR) camera. From the result, it is understood that the natural fiber-reinforced gears can be used for smooth and noiseless operation especially in intermittent applications.
\end{abstract}

Keywords: Natural Fiber-Reinforced Gears; Dynamic Testing; Scanning Electron Microscope (SEM) Analysis; FLIR camera

\section{Introduction}

Polymeric gears are chosen for low power application such as gear motors for electromechanical actuators, gear pumps, billet roller cams, and drive shafts for car, and so on, over metal gears for its advantages like less weight, noiseless operation, minimal or no lubrications, and good corrosion resistance. However, the mechanical property requirement can be achieved by using reinforcement to increase the specific strength. The common reinforcement in plastics are glass fibers. In the recent years, researchers have shown interest in using natural fiber as a reinforcement in plastics as it has less density, good specific strength, and is also biodegradable.

Many studies are ongoing in this regard, Hirogaki et al. [1] found out that glass fiber shows unacceptable wear phenomenon under power transmission compared with carbon fiber-reinforced gears, and hence finds wider applications, although the cost of the gear is high. The lead deviation phenomenon is observed by Senthilvelan et al. [2] who found that glass fiber-reinforced gears exhibited a higher lead deviation than unreinforced gears, and many more findings prove the importance of identifying some other potential reinforcements, thus researchers started working on natural fiber reinforced composites. Satyanarayana et al. [3] says that research and development of biodegradable composites will help in meeting local demand too, as the abundant biodegradable materials available in any region can be used for possible manufacturing of products with their prevailing technologies. Joseph et al. [4] used banana/sisal hybrid fiber-reinforced polyester composites that resulted in good 
tensile and flexural properties. Saxena et al. [5] based on many reviews, found that plant fiber is a better replacement for synthetic fiber in terms of cost, density, renewability, and $\mathrm{CO}_{2}$ emission.Ramesh et al. [6] found that sisal/glass fiber composite performs well with the tensile load. Shah et al. [7] have proven that flax is a suitable structural replacement for E-glass for small wind turbine blade applications. Ramnath et al. [8] found that the banana and jute hybrid composite shows good performance. Recently, many research works have been carried out on incorporating additives to improve the performance of natural fiber reinforced composites. Xia et al. [9] found out that adding powder activated carbon along with kenaf fiber reinforced polyester has more effect on electromagnetic interference signal absorption, but it reduces the mechanical strength of the natural fiber composite. Xia et al. [10] again, in another work, found that low density of the inorganic nanoparticle impregnated and treated natural fiber/polyester composite has good specific mechanical properties, which exceeded that of glass-fiber sheet molding compounds (SMC). Therefore, kenaf-fiber-reinforced composites have high possibility to replace glass-fiber SMC in the automotive industries. Xia et al. [11] say that adding hybrid boronnitride (hBN) with natural fibers will improve the thermal conductivity. The results from dynamic mechanical tests proved that performances dramatically improved after adding kenaf fibers into the hBN/epoxy composite. Meenakshiet al. [12] found that hybridizing the natural fiber with glass fiber improves the mechanical strength of the material, especially tensile and flexural strength. The above-mentioned research works show the potential and scope of natural fiber reinforced composites as an engineering material.

In this work, natural fibers, flax, and sisal are reinforced in polyester resin, and gears are fabricated using molding method with 15 and 20\% above-mentioned fibers as reinforcement. Also, in the same percentage glass, fiber-reinforced gears are fabricated to carry out a comparative study. All the fabricated-gears are dynamically tested and their tooth wear is studied by measuring the tooth reduction using scanning electron microscope (SEM) analysis and weight reduction is also monitored. Further, thermal performance/heat withstanding capacities are also noted down using thermal imaging contact less infra-red temperature (FLIR) cameraunit.

\section{Experimentation}

\subsection{Design of Gear}

The gear chosen is a 40-tooth lathe gear for $50 \mathrm{rpm}$. This particular gear is selected from the same lathe where the dynamic test has been performed; all the major dimensions of the gear are given in Table 1.

Table 1. Gear Specification.

\begin{tabular}{ccc}
\hline Serial Number & Parameter & Value \\
\hline 1 & Number of teeth (N) & 40 \\
2 & Pitch circle diameter (PCD) & $64 \mathrm{~mm}$ \\
3 & Base Circle Diameter & $60 \mathrm{~mm}$ \\
4 & Module (m) & 1.6 \\
5 & Face Width (b) & $16 \mathrm{~mm}$ \\
6 & Diametrical Pitch & $0.625 \mathrm{~mm}$ \\
7 & Addendum (A) & $1.6 \mathrm{~mm}$ \\
8 & Dedendum (D) & $2 \mathrm{~mm}$ \\
\hline
\end{tabular}

\subsection{Fabrication of Composite Gears}

Using the steel gear as the pattern, a fiber-reinforced polyester (FRP) mold is created. The polyester resin is mixed with hardener and accelerator in the ratio of 10:1. In the mixture, chopped sisal, flax, and glass fibers of $6 \mathrm{mminlength} \mathrm{[13]} \mathrm{are} \mathrm{mixed} \mathrm{in} \mathrm{the} \mathrm{weight} \mathrm{fraction} \mathrm{of} 20 \%$ and $15 \%$ to the resin, that is, the resin hardener mixture is impregnated with chopped fibers in the above-mentioned weight percentage. The fiber weight percentage is fixed based on the findings in [14], where the authors have 
compared the performance of 5\%,10\%, 15\%, and 20\% sisal fiber reinforced polymeric gears. It was found that in $15 \%$ fiber reinforced gear, the wear damage is lesser and in $20 \%$ fiber reinforced gears, the heating effect and wear rate are $15 \%$ and $36 \%$ lesser.

The mixture is poured in to silicon coated mold and allowed to cure for $24 \mathrm{~h}$ and the gears are carefully removed from the mold and dried in room temperature for $24 \mathrm{~h}$, colour pigments are added in the mixture to differentiate the gears. The various stages of gear fabrication are shown in Figure 1. Wit each of the three fibers, namely, sisal, flax, and glass, three specimens were prepared with two different weight percentages, $15 \%$ and $20 \%$. Thus, a total of 18 specimens were used for testing. Samples of each type are shown in Figure 2.
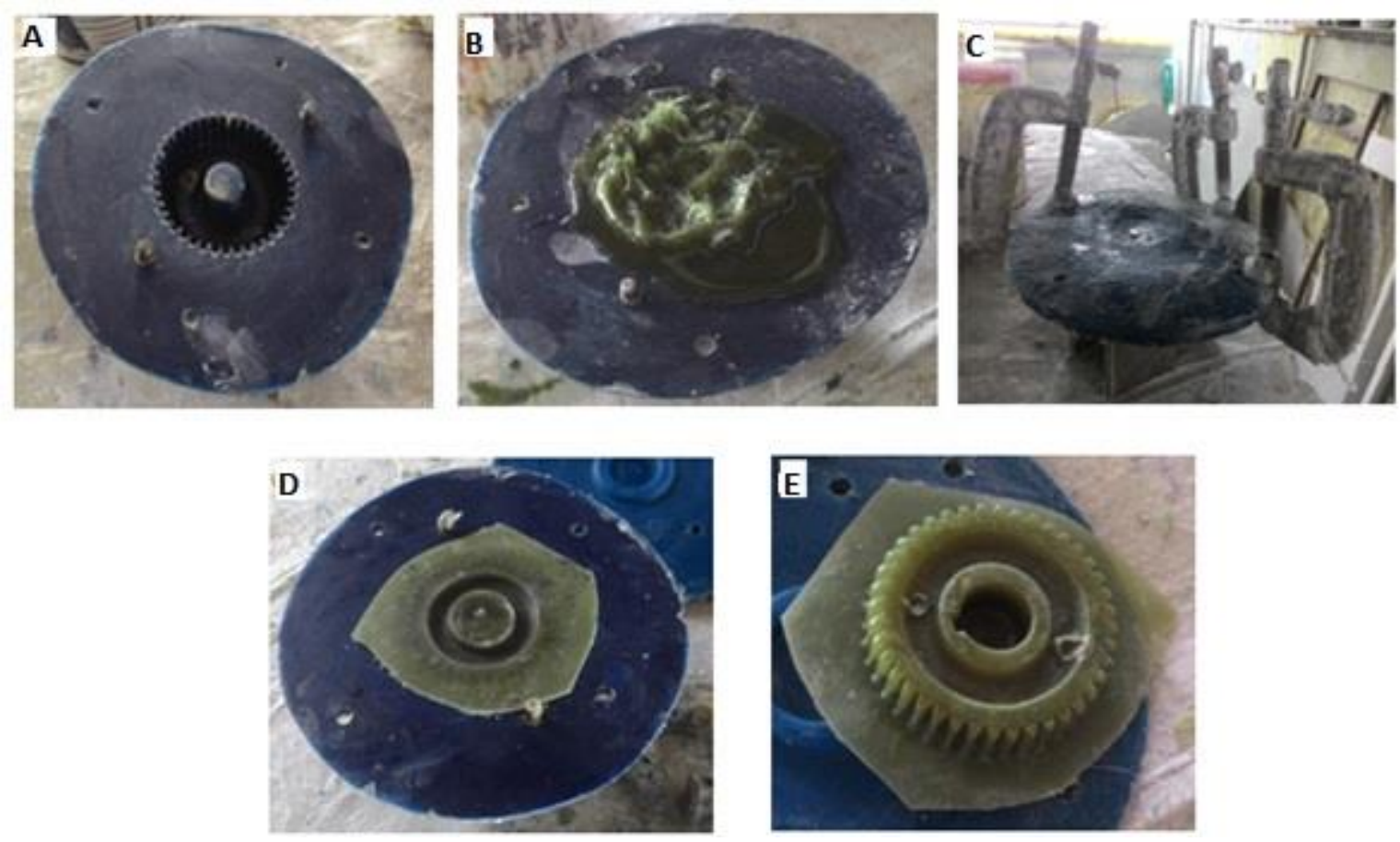

Figure 1. (A) Mold for gear. (B) Moldfilled with resin and fiber. (C) Mold compressed with c-clamp. (D) Product in the mold. (E) Final product.

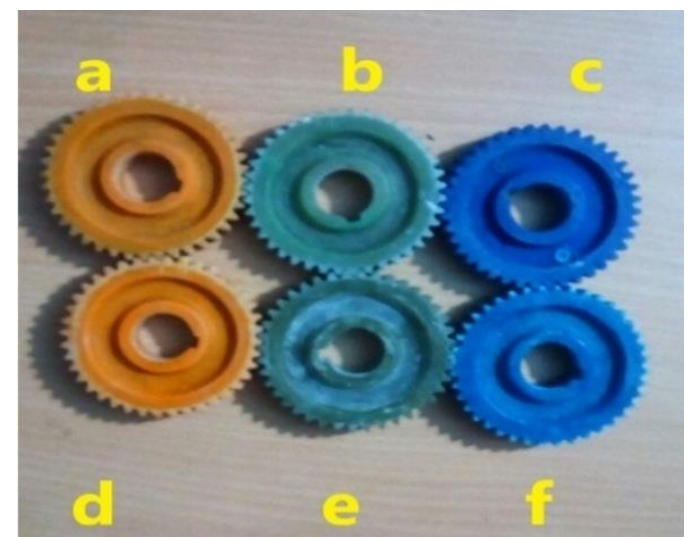

Figure 2. (a) Flax fiber-reinforced polyester gear (FFRPG)-20. (b) Sisal FRPG (SFRPG)-20. (c) Glass FRPG (GFRPG)-20. (d) FFRPG-15. (e) SFRPG-15. (f) GFRPG-15. 


\subsection{Dynamic Testing}

The dynamic testing was done on a lathe of Anil Heavy Machines at 150 RPM in the temperature range of $30-35{ }^{\circ} \mathrm{C}$; humidity is maintained at $60 \% \pm 10 \%$. A similar metal gear with 40 teeth of the lathe was swapped with the fabricated gears one by one and was then run for $1 \mathrm{~h}$, leaving an appropriate time interval for other parts of the machine to cool down. The running test was performed by mating plastic gear with steel gear as done by Hirogaki et al. [1].

Senthilvelan et al. [15] say that the heat generated in gears is a result of heat and the hysteresis effect, friction, as well as the hysteresis loss increases with increase in gear rotational speed; therefore, the speed is maintained constant for all the gears to achieve single conclusion for low speed. The initial weights of the gears as well as the temperatures of the gears were measured with the contactless infra-red temperature camera (FLIR E6, FLIR Systems Inc., Wilsonville, OR, USA) before running. After one hour, the temperatures and the weight reduction due to wear are once again measured and tabulated. The meshed gear in the lathe and the FLIR measurement are shown in Figure 3A,B.
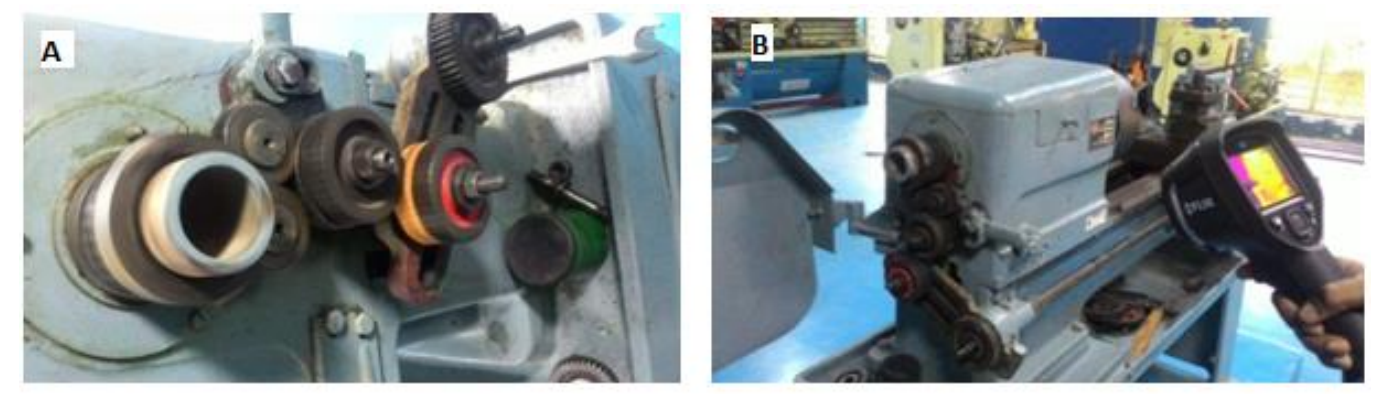

Figure 3. (A) Flax fiber-reinforced gear in mesh with metal gear. (B) Contactless infra-red temperature (FLIR) temperature measurement.

\subsection{Scanning Electron Microscopic Analysis}

The machine used for SEM analysis is a TESCAN Vega 3 (TESCAN USA Inc., Warrendale, PA, USA), as shown in Figure 4A, which is a versatile system intended for both low and high vacuum operations. A portion of the gear teeth was cut as a sample piece as in Figure 4B.
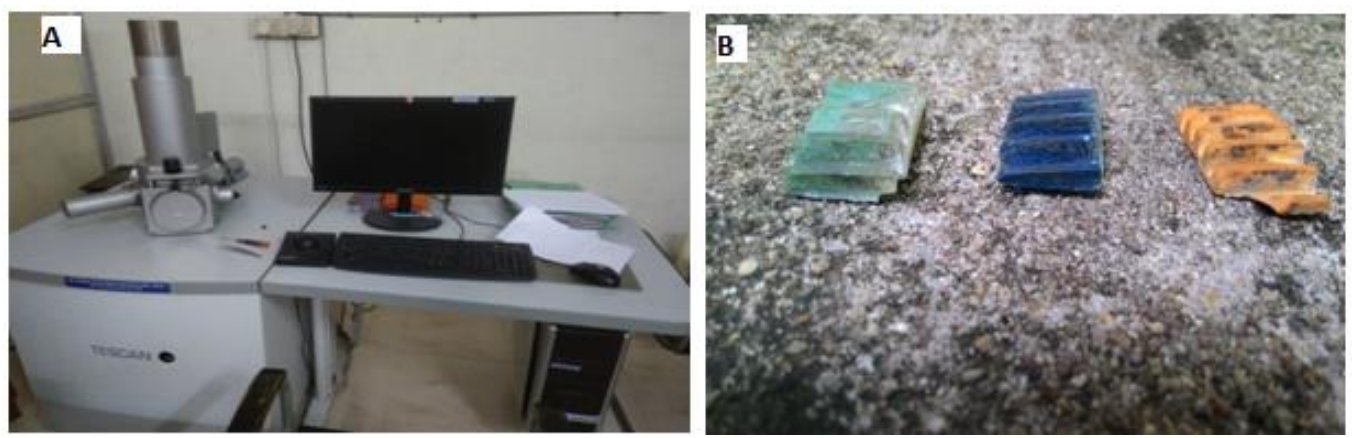

Figure 4. (A) Scanning electron microscopes. (B) Test samples.

\section{Results and Discussion}

\subsection{Dynamic Test Results}

Figure 5 shows a comparision ofinitial and final thickness for all the gears. Reduction percentage in the $20 \%$ fiber-reinforced gears is less than that of $15 \%$ fiber reinforced gears, in that the tooth reduction in $20 \%$ flax fiber-reinforced gear is much less compared with the other types. The lower percentage of wear in natural fiber-reinforced gears is a result of the non-brittle nature of the natural fibers. 


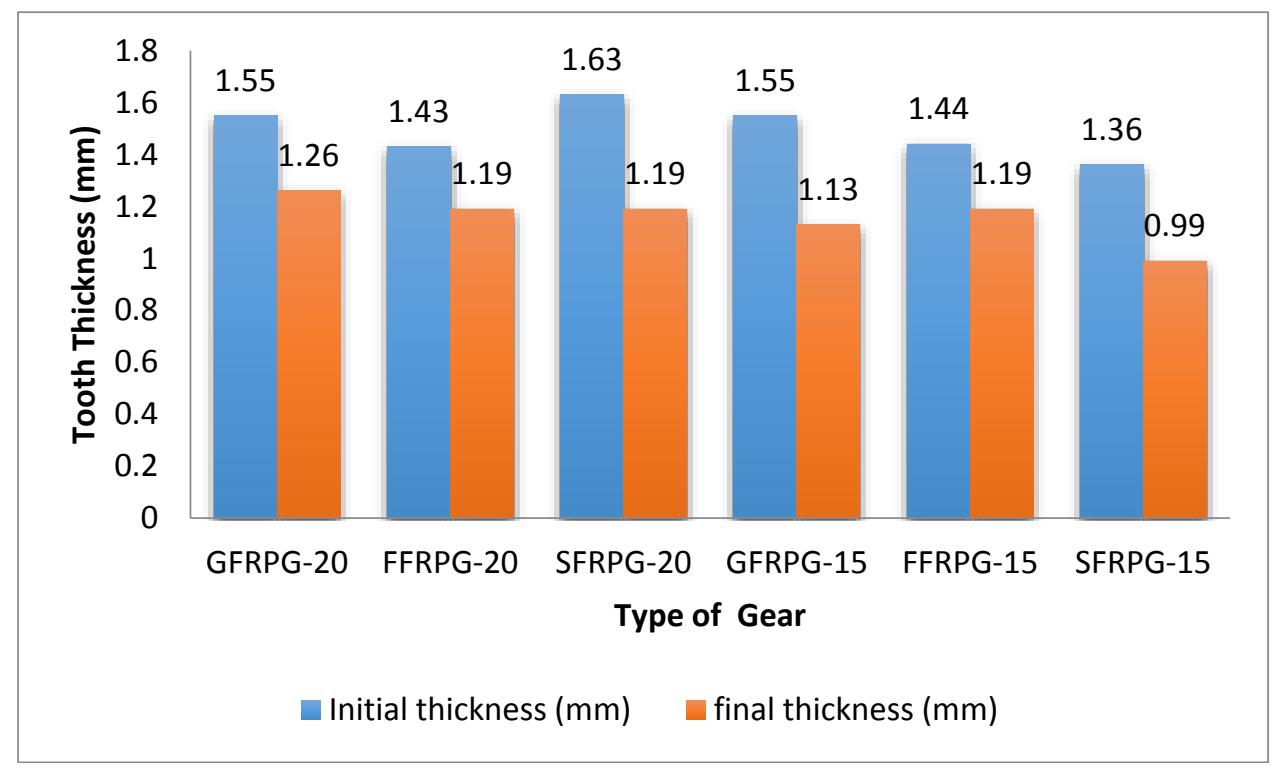

Figure 5. Comparision ofinitial and final thickness for all the gears.

The weight reduction in the gears before and after running was measured using a $0.1 \mathrm{mg}$ accurate weighing machine. Figure 6 shows the comparison of initial and final weight for all the gears. Glass fiber-reinforced gears show the highest percentage of reduction, whereas the reduction percentage in natural fiber-reinforced gears is less than $1 \%$. The main aim of this work is not comparing metal and polymeric gear, which has been done by many researchers already, including a notable work by Mahebubet et al. [16]. The aim of this work is to replace or compare glass fiber reinforced polymeric gears with natural fiber reinforced gears, which has been shown clearly.

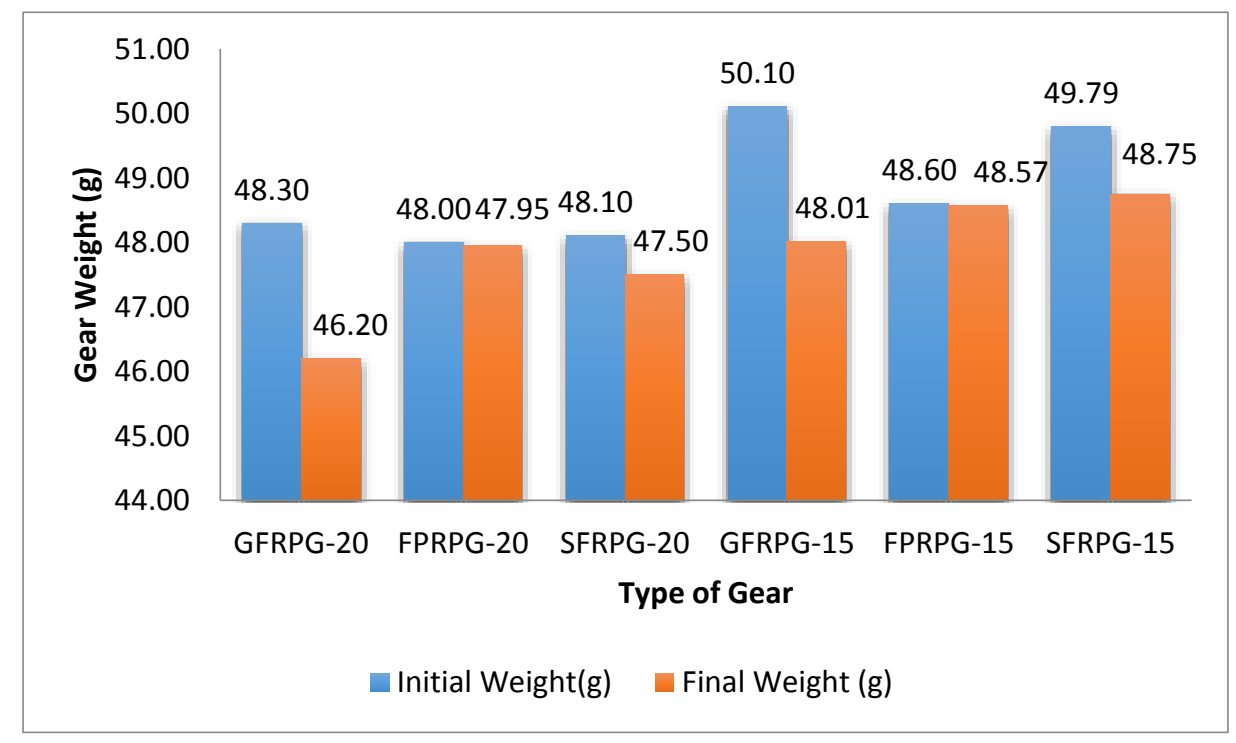

Figure 6. Comparision of initial and final weights of all the gears.

The weight of the metal gear considered as reference is $235 \mathrm{~g}$, which is almost six times greater than that of polymeric gears. Moreover, the comparison is done with glass fiber reinforced gear too, which fails after running for less than half an-hour. Hence, the natural fiber reinforced gears are tested for one hour, which is double that of glass fiber reinforced gears' testing time. The SEM images of gear tooth wear and fiber pull outs of all the gears are shown in Figures 7 and 8. 

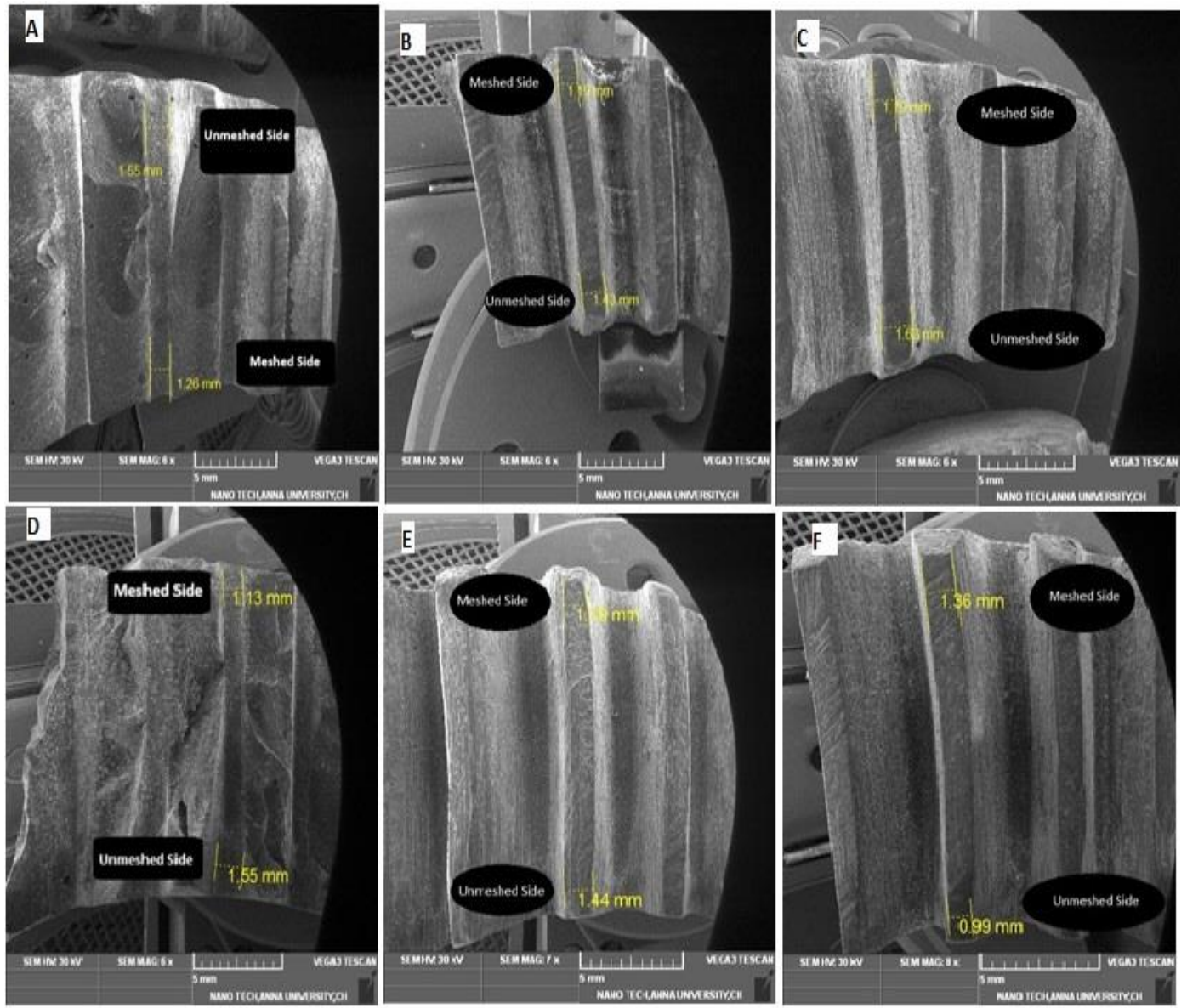

Figure 7. Reduction in tooth thickness. (A) GFRPG-20. (B) FFRPG-20. (C) SFRPG-20. (D) GFRPG-15. (E) FFRPG-15. (F) SFRPG-15.
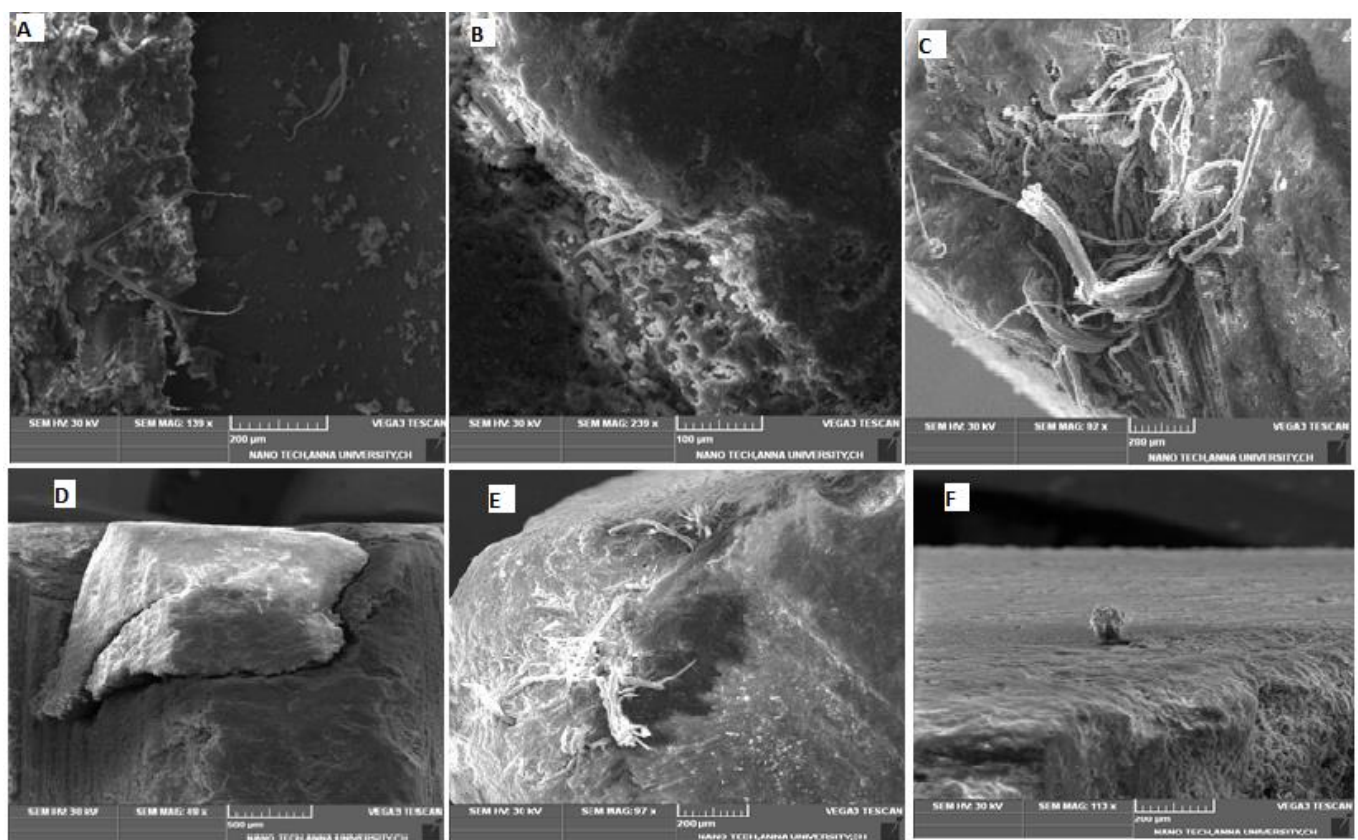

Figure 8. Fiber pull outs. (A) GFRPG-20. (B) FFRPG-20. (C) SFRPG-20. (D) Tooth break after 20 min of running in GFRPG-15. (E) FFRPG-15. (F) SFRPG-15. 


\subsection{Thermal Analysis Using FLIR Camera}

The surface temperature of the gear increases while running, even though the rotational speed is kept constant; the temperature of the surface may rise because of continuous running. This rise in temperature of the surface is measured using one of the latest devices, an FLIR camera (FLIR Systems, Inc. Wilsonville, OR, USA), which is a new innovation in inspection tools, with this contactless measuring system, the surface temperature before and after running the gear for $1 \mathrm{~h}$ can be easily noted, and the same can be tabulated, as in Table 2. The images recorded for various gears in the FLIR are shown in Figures 9 and 10. As a result of high thermal conductivity and the brittle nature of the glass fiber, the temperature of the glass fiber-reinforced gears rises, when it reaches $37^{\circ} \mathrm{C}$ in $15 \%$ fiber and $43{ }^{\circ} \mathrm{C}$ in $20 \%$ fiber, which is after $20 \mathrm{~min}$ of running, the gear tooth breaks. Whereas the natural fiber-reinforced gears, irrespective of the weight percentage of fiber, run successfully for $1 \mathrm{~h}$ in mesh with the metal gear at $150 \mathrm{rpm}$ until $42^{\circ} \mathrm{C}$. A comparison of maximum initial and final temperature of the gears is shown in Figure 11.

Table 2. Temperature rise in gears after running for $1 \mathrm{~h}$ at $150 \mathrm{rpm}$. Flax fiber-reinforced polyester gear (FFRPG), sisal FRPG (SFRPG), glass FRPG (GFRPG).

\begin{tabular}{ccc}
\hline Gear Type & Initial Temperature $\left({ }^{\circ} \mathrm{C}\right)$ & Final Temperature $\left({ }^{\circ} \mathrm{C}\right)$ \\
\hline GFRPG-20 & $31.7-35.8$ & $33.1-37.1$ \\
FFRPG-20 & $35.1-41.5$ & $35.4-42.6$ \\
SFRPG-20 & $32.7-36.8$ & $33.5-42.6$ \\
GFRPG-15 & $33.5-37.2$ & $36.2-43.5$ \\
FFRPG-15 & $31.7-35.7$ & $33.9-41.6$ \\
SFRPG-15 & $32.7-41.3$ & $34.8-42.4$ \\
\hline
\end{tabular}
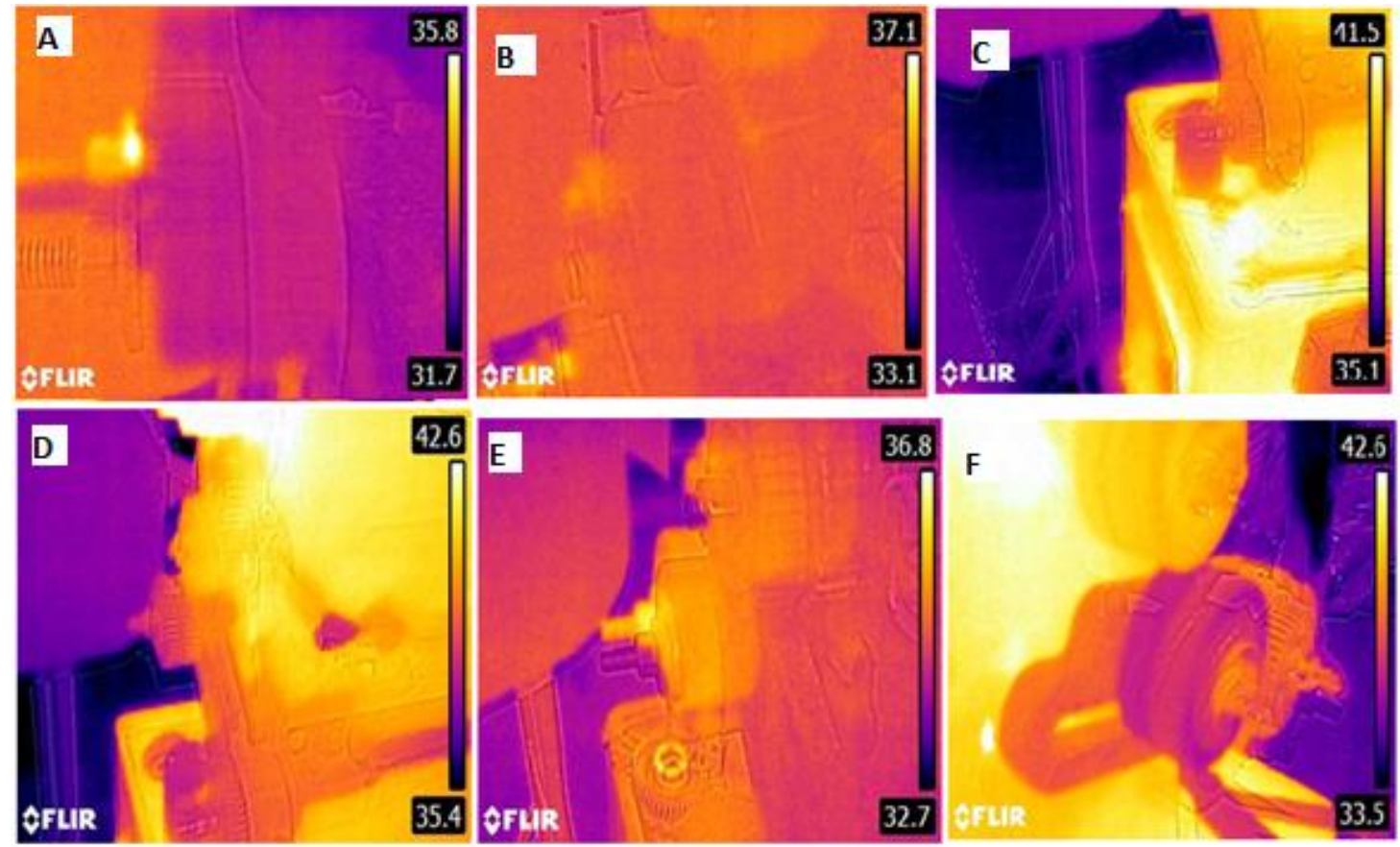

Figure 9. Thermal images. (A) Initial temperature of GFRPG-20. (B) Final temperature of GFRPG-20. (C) Initial temperature of FFRPG-20. (D) Final temperature of FFRPG-20. (E) Initial temperature of SFRPG-20. (F) Final temperature of SFRPG-20. 


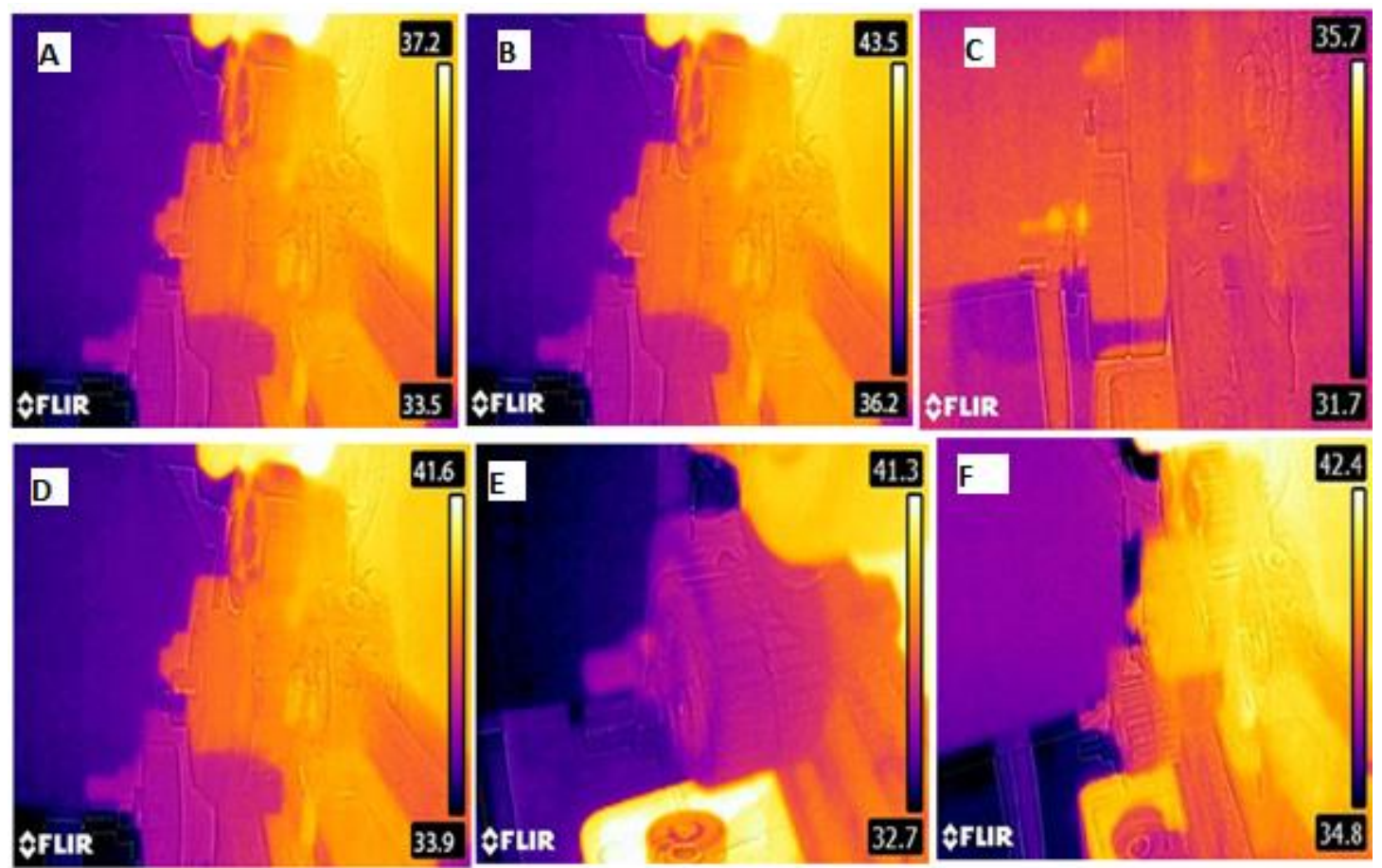

Figure 10. Thermal images. (A) Initial temperature of GFRPG-15. (B) Final temperature of GFRPG-15. (C) Initial temperature of FFRPG-15. (D) Final temperature of FFRPG-15. (E) Initial temperature of SFRPG-15. (F) Final temperature of SFRPG-15.

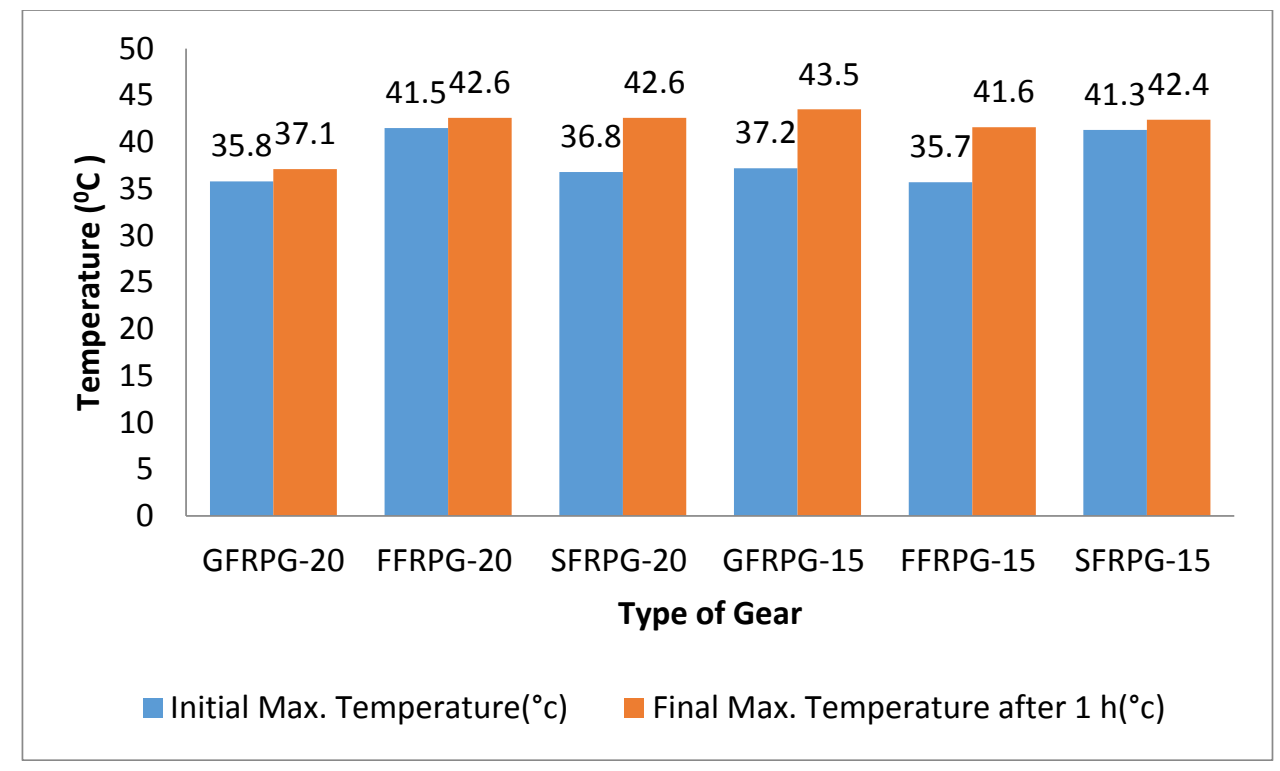

Figure 11. Comparision of initial and final temperaturesof all gears.

Wu et al. [17] found out that natural fiber reinforced composite has shown outstanding mechanical properties compared with those of the glass fiber sheet molding component. Saxena et al. [5] listed the tensile and flexural strength of flax and sisal fiber reinforced polyester. Also, references [5,18] discussed the mechanical strength of these materials. As it is already proven that natural fiber-reinforced composites are very well competitive with glass fiber composites in terms of mechanical strength, the present work is focused on product testing. 


\section{Conclusions}

From various research surveys, it is understood that for polymeric gears, wear, microstructure surface condition monitoring, weight loss, and thermal damage are the most prominent methods to detect failures [19]. This research work deals very well with all the above parameters and the following conclusions are made:

- The fabrication of fiber-reinforced gear is very economical and simple by room temperature molding method.

- The SEM analysis shows that the reduction in tooth thickness after running the gear for $1 \mathrm{~h}$ is more in glass fiber-reinforced gear, even though it fails after $30 \mathrm{~min}$, whereas the tooth wear is less for flax reinforced gears.

- The weight reduction of glass fiber-reinforced gears is $2 \%$, whereas for natural fiber-reinforced gears, it is less than $1 \%$.

- The temperature study using FLIR camera shows that the natural fiber-reinforced gears run until $42{ }^{\circ} \mathrm{C}$, whereas the glass fiber gears failed at $37^{\circ} \mathrm{C}$.

From the above observations, it is understood that the natural fiber-reinforced gears can be recommend for potential applications for noiseless and smooth operation.

Author Contributions: C.M.M.D. performed the experiments and draft the initial version of the article. K.A. designed the experiments, monitored the conduction of experiments and reviewed the manuscript. Both the authors contributed to the analysis of the data and approved the final version of the manuscript.

Funding: This research received no external funding.

Conflicts of Interest: The authors declare no conflicts of interest.

\section{Nomenclature}

$\begin{array}{ll}\text { GFRPG-20 } & \text { 20\% Glass Fiber-Reinforced Polyester Gear } \\ \text { FFRPG-20 } & \text { 20\% Flax Fiber-Reinforced Polyester Gear } \\ \text { SFRPG-20 } & \text { 20\% Sisal Fiber-Reinforced Polyester Gear } \\ \text { GFRPG-15 } & \text { 15\% Glass Fiber-Reinforced Polyester Gear } \\ \text { FFRPG-15 } & \text { 15\% Flax Fiber-Reinforced Polyester Gear } \\ \text { SFRPG-15 } & 15 \% \text { Sisal Fiber-Reinforced Polyester Gear }\end{array}$

\section{References}

1. Hirogaki, T.; Aoyama, E.; Katayama, T.; Iwasaki, S.; Yagura, Y.; Sugimura, K. Design systems for gear elements made of cotton fiber-reinforced plastics. Compos. Struct. 2004, 66, 47-52. [CrossRef]

2. Senthilvelan, S.; Gnanamoorthy, R. Influence of reinforcement on composite gear metrology. Mech. Mach. Theory 2008, 43, 1198-1209. [CrossRef]

3. Satyanarayana, K.G.; Arizaga Gregorio, G.C.; Wypych, F. Biodegradable composites based on lingo cellousic fibers-Anoverview. Prog. Polym. Sci. 2009, 34, 982-1021. [CrossRef]

4. Joseph, M.I.K.; Thomas, S. Mechanical Performance of Short Banana/Sisal Hybrid Fiber Reinforced Polyester composite. J. Reinf. Plast. Compos. 2010, 29, 12. [CrossRef]

5. Saxena, M.; Pappu, A.; Sharma, A.; Haque, R.; Wankhede, S. Composite materials from natural resource: Recent trends and future potentials. In Advance in Composite Materials-Analysis of Natural and Man-Made Materials; Intech: London, UK, 2011; pp. 121-162. ISBN 978-953-307-449-8. Available online: www.intechopen. com (accessed on 22 July 2015).

6. Ramesh, M.; Palanikumar, K.; Reddy, K.H. Mechanical property evaluation of sisal-jute-glass fiber reinforced polyester composites. Compos. Part B Eng. 2013, 48, 1-9. [CrossRef]

7. Shah, D.U.; Schubel, P.J.; Clifford, M. Can Flax Replace E-Glass in structural composites? A small wind turbine blade case study. Compos. Part B Eng. 2013, 52, 172-181. [CrossRef] 
8. Ramnath, B.V.; Sharavanan, R.; Chandrasekaran, M.; Elanchezhian, C.; Sathyanarayanan, R.; Raja, R.N.; Kokan, S.J. Experimental Determination of Mechanical Properties of Banana Jute Hybrid composite. Fiber Polym. 2015, 16, 164-172. [CrossRef]

9. Xia, C.; Zhang, S.; Ren, H.; Shi, S.Q.; Zhang, H.; Cai, L.; Li, J. Scalable Fabrication of Natural-Fiber Reinforced Composites with electromagnetic Interference Shielding Properties by Incorporating PowderedActivated Carbon. Materials 2016, 9, 10. [CrossRef] [PubMed]

10. Xia, C.; Shi, S.Q.; Wu, Y.; Cai, L. High pressure-assisted magnesium carbonate impregnated natural fiber-reinforced composites. Ind. Crop. Prod. 2016, 86, 16-22. [CrossRef]

11. Xia, C.; Garcia, A.C.; Shi1, S.Q.; Qiu, Y.; Warner, N.; Wu, Y.; Cai, L.; Rizvi, H.R.; D'Souza1, N.A.; Nie, X. Hybrid boron nitride-natural fiber composites for enhanced thermal conductivity. Sci. Rep. 2016, 6, 34726. [CrossRef] [PubMed]

12. Meenakshi, C.M.; Krishnamoorthy, A. Mechanical Characterization and Comparative Evaluation of the Different Combination of Natural and Glass Fiber Reinforced Hybrid Epoxy Composites. In Advanced Manufacturing and Materials Science. Lecture Notes on Multidisciplinary Industrial Engineering; Antony, K., Davim, J., Eds.; Springer: Cham, Switzerland, 2018.

13. Kurian, A.J.; Mathew, V.; Sivasubramanian, P. Optimization of fiber length and fiber weight fraction in natural fiber reinforced composites. IJTARME 2014, 3, 2319-3182.

14. Rahman, A.F.; Kumar, A.P.S.; Giriraj, B.; Arun, A.P.; Santhosh, R. Performance of Polymer gears reinforced with sisal woven rovings. Carbon Sci. Technol. 2014, 6, 41-48.

15. Senthilvelan, S.; Gnanamoorthy, R. Effect of rotational speed on the performance of unreinforced and glass fiber reinforced Nylon 6 spur gears. Mater. Des. 2007, 28, 765-772. [CrossRef]

16. Mahebub, V.; Kevin, V. Comparative Finite Element Analysis of Metallic and Non Metallic Spur Gear. IOSR J. Mech. Civ. Eng. 2014, 11, 136-145.

17. Wu, Y.; Xia, C.; Cai, L.; Garcia, A.C.; Shi, S.Q. Development of natural fiber-reinforced composite with comparable mechanical properties and reduced energy consumption and environmental impacts for replacing automotive glass-fiber sheet molding compound. J. Clean. Prod. 2018. [CrossRef]

18. Mohammed, M.H.; Dauda, B. Unsaturated Polyester Resin Reinforced With Chemically Modified Natural Fibre. J. Polym. Text. Eng. 2014, 1, 31-38.

19. Ghazali, W.M.; Idris, D.M.N.D.; Sofian, A.H.; Siregar, J.P.; Aziz, I.A.A. A review on failure characteristics of polymer gear. In Proceedings of the 2nd International Conference on Automotive Innovation and Green Vehicle, Cyberjaya, Malaysia, 2-3 August 2016. [CrossRef] 